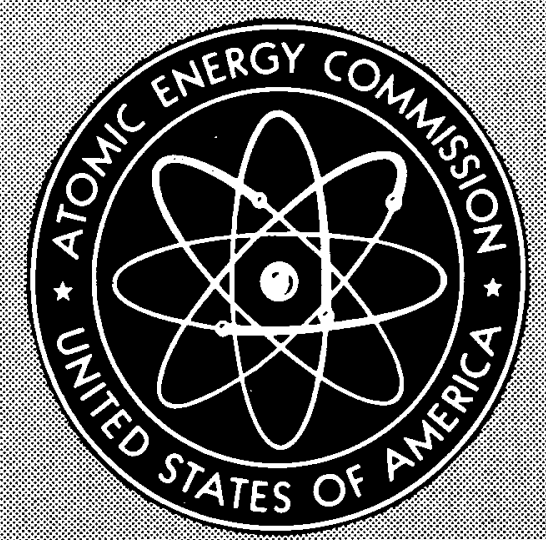

APDA-160

\title{
DESIGN AND ECONOMIC EVALUATION OF MOBILE BLANKETS FOR FAST REACTORS
}

By
A. E. Klickman
W. H. Jens
G. L. Ball
B. M. Segal
A. Amorosi
R. C. Williams
J. J. Edwards

March 10, 1964

Atomic Power Development Associates, Inc.

Detroit, Michigan 


\section{DISCLAIMER}

This report was prepared as an account of work sponsored by an agency of the United States Government. Neither the United States Government nor any agency Thereof, nor any of their employees, makes any warranty, express or implied, or assumes any legal liability or responsibility for the accuracy, completeness, or usefulness of any information, apparatus, product, or process disclosed, or represents that its use would not infringe privately owned rights. Reference herein to any specific commercial product, process, or service by trade name, trademark, manufacturer, or otherwise does not necessarily constitute or imply its endorsement, recommendation, or favoring by the United States Government or any agency thereof. The views and opinions of authors expressed herein do not necessarily state or reflect those of the United States Government or any agency thereof. 


\section{DISCLAIMER}

Portions of this document may be illegible in electronic image products. Images are produced from the best available original document. 


\section{LEGAL NOTICE}

This report was prepared as an account of Government sponsored work. Neither the United States, nor the Commission, nor any person acting on behalf of the Commission:

A. Makes any warranty or representation, expressed or implied, with respect to the accuracy, completeness, or usefulness of the information contained in this report, or that the use of any information. apparatus, method, or process disclosed in this report may not infringe privately owned rights; or

B. Assumes any liabilities with respect to the use of, or for damages resulting from the use of any information, apparatus, method, or process disclosed in this report.

As used in the above, "person acting on behalf of the Commission" includes any employee or contractor of the Commission, or employee of such contractor, to the extent that such employee or contractor of the Commission, or employee of such contractor prepares, disseminates, or provides access to, any information pursuant to his employment or contract with the Coinmission, or his employment with such contractor.

This report has been reproduced directly from the best available copy.

Printed in USA. Price $\$ 1.25$. Available from the Clearinghouse for Federal Scientific and Technical Information, National Bureau of Standards, U. S. Department of Commerce, Springfield, Va. 
APDA-160

REACTOR TECHNOLOGY

(TW-4500, 32nd. Ed.)

\section{DESIGN AND ECONOMIC EVALUATION OF MOBILE BLANKETS FOR FAST REACTORS}

AEC Contract AT(11-1)-865, Project 8, Task III

A. E. Klickman
A. Amorosi
W.H. Jens
G. L. Ball
B. M. Segal
J. J. Edwards
R. C. Williams

March 10, 1964 


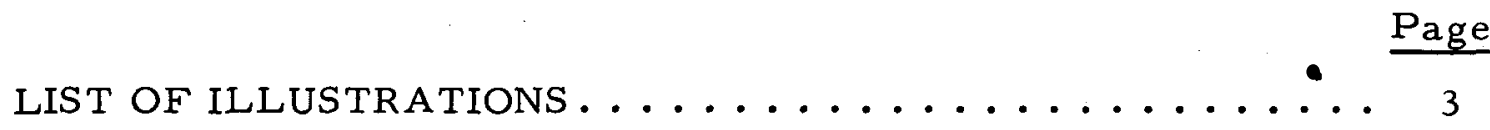

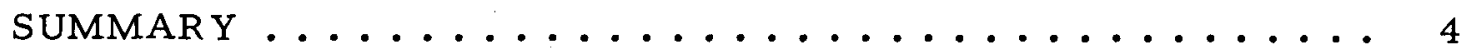

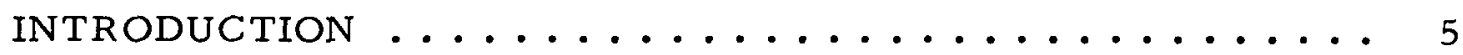

BATCH-MOBILE-FUEL -MANAGEMENT CONCEPT . . . . . 11

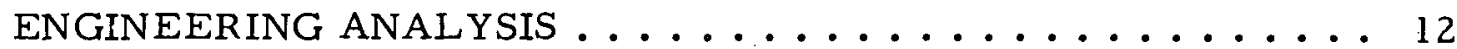

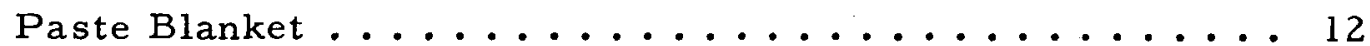

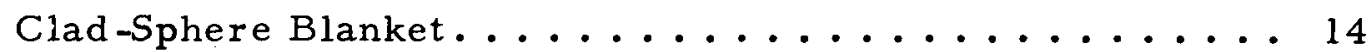

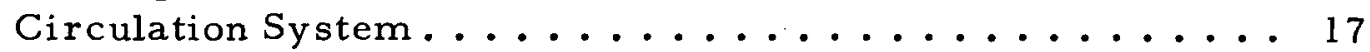

FABRICATION COSTS OF MOBILE BLANKETS ......... 19

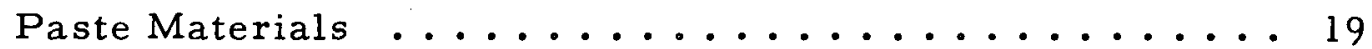

Settled-Bed Materials.................... 20

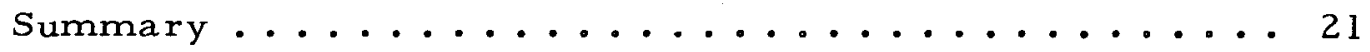

ECONOMIC ANALYSIS ...................... 24

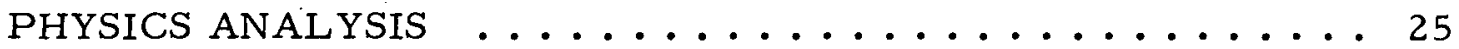

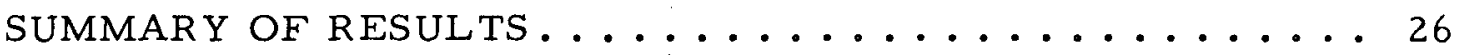

COMPARISON OF MOBILE SYSTEMS ............. . . 34

COMPARISON OF MOBILE BLANKETS WITH FIXED

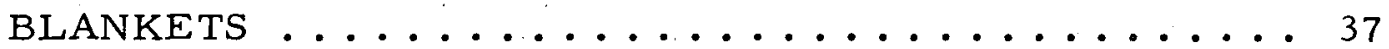

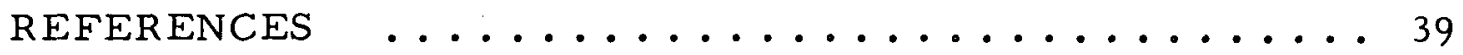

APPENDIX I - THE CHOICE OF A CERAMIC MATERIAL

AS A PASTE DISPERSANT .......... 40

APPENDIX II - ASSUMED FABRICATION PROCESSES FOR PASTE AND SETTLED-BED BLANKET

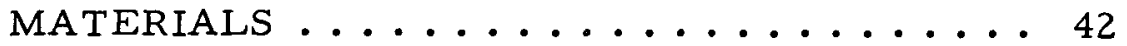

APPENDIX III - PHYSICS ANALYSIS OF MOBILE SYSTEMS _ . 46 


\section{LIST OF ILLUSTRATIONS}

Figure

Title

$\underline{\text { Page }}$

1

Outside Diameter and Spacing of Cooling

Tubes for Paste Concept .............

Porosity as a Function of the Ratio of Sphere

Diameter to Bed Diameter ........... 16

3

Internal Heat Generation of Blanket

Sphere and Diameter of Fuel Sphere ........

Profit and End-of-Life Heat Generation Rate

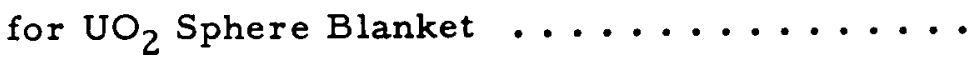

Profits for Mobile Blankets .............

\section{LIST OF TABLES}

Table

Title

$\underline{\text { Page }}$

I

Core Characteristics .............. 8

II

Blanket Design Limitations $\ldots \ldots \ldots$

III

Summary of Results for Clad-Sphere Blankets .. 27

IV

Physics Data for Clad-Sphere Systems ..... 28

V

Summary of Results for Paste Systems ... . 29

VI

Engineering Design Data for Paste Systems .... 30

VII

Physics Data.for Paste Systems ......... 31

VIII

Representative Data for Economic Comparisons . 


\section{SUMMARY}

In recent years several new blanket concepts for fast reactors have been advanced and the basic technical feasibility of each has been investigated. Two of these concepts, which have beer selected for further study, are discussed in this report. One is a slowly circulating paste concept in which small fuel particles are dispersed in sodium, which serves as the carrier medium but not as a heat-transport medium. The other is a clad-sphere concept, in which small spheres of fuel (about 0.5 inch diameter) are slowly circulated through the reactor with sodium coolant flowing around them to remove heat.

In a previous study of fixed-blanket designs, it was found that such a blanket is limited economically by the radial and axial distributions in burnup, heat generation, and plutonium concentration. But no such limitation exists if a mobile form of blanket fuel material is employed. This study, then, is confined to mobile concepts.

The study, embodying a fixed set of ground rules, covers the physics, engineering, and economic considerations of the concepts. Relative to the latter consideration, a specific blanket design for each was selected that would effect optimum blanket economics; and a fixed blanket of $\mathrm{UO}_{2}$ pins was chosen as a standard for comparison of the concepts. To add breadth to the study, each concept was investigated for use with a uranium alloy as well as with a ceramic fuel such as $\mathrm{UO}_{2}$ or UC.

It was concluded from the study that - - assuming identical fuel material and economically optimized systems -- the paste concept is more economical than the clad-sphere concept. Further, it was found that both mobile blanket concepts are generally more attractive economically when a ceramic fuel material is used than when a uranium alloy fuel material is used. In addition, it was found that systems using the paste concept can be designed that will be economically attractive when compared with a blanket of fixed oxide pins. It would; therefore, appear that this concept should be studied further to allow its early use in a reactor experiment. 


\section{INTRODUCTION}

The designs of the fast reactors that are now in operation or about to go into operation have included thick blankets for several reasons. High plutonium prices and low estimates of fabrication and reprocessing costs indicated the economic feasibility of thick blankets. The desire to demonstrate breeding with U -235 fuel also influenced that choice of thick blankets. Finally, the neutron absorption in a thick blanket protects the reactor vessel wall against radiation damage that would occur if the blanket were thinner. Currently, most reactor studies being made follow the practice of using thick blankets, because little effort has been devoted to the economic analysis of breeder blankets.

The basic purpose of this study is to evaluate advanced blanket concepts such as a paste bed of sodium and fuel material and a packed bed of spheres of blanket fuel material. Such concepts must be examined, not only for their own values, but also for their values relative to those of present-day blanket designs. Toward this end, a study was made of design criteria, the results of which were applied to fixed-blanket designs. The design and economic evaluation of the fixed blankets that were studied are reported in Reference 1.

As a continuation of the over-all evaluation of advanced-blanket concepts for fast reactors, a study has been made of mobile blankets. This study has taken into account the engineering, physics, and economics of two concepts, clad spheres and paste, with the consideration of fuel materials, $\mathrm{U}-3 \mathrm{w} / \mathrm{o} \mathrm{Mo}, \mathrm{UO}_{2}$, and UC. Designs were established that optimize the economics for a set of engineering and economic ground rules consistent for the two designs and reasonable in terms of presentday technology.

To appreciate the need for the study of advanced blanket concepts, it is necessary to review some of the results on conventional fixed-blanket concepts that were reported in Reference 1 .

For fixed blankets it was found that the limitations of present-day fuel material (especially burnup) acted as limits to high blanket profits. Within a blanket.subassembly, the maximum-to-average value for the flux was found to be about 2.5. But since the end-of-life, maximum-to-average value for the plutonium concentration was also found to be about 2.5 , the end-of-life, maximum-to-average value for the rate of heat generation would be about 6 and the maximum-to-average value for burnup would also be about 6 . This means that blanket fuel material has reached its burnup limitation at the point of maximum burnup when the average 
burnup in a subassembly is only at one -sixth of the limiting burnup. If, however, burnup were to be evenly distributed, the lifetime of the fuel material would be increased considerably. Profits, too, would increase due to the lengthened period of time over which fabrication costs could be amortized.

An obvious method to achieve a better distribution of the burnup is to make the fuel mobile. With this concept, even though maximum -toaverage values for flux and rate of heat generation do exist, burnup and plutonium buildup are evenly distributed throughout the blanket material. Thus, maximum economic potential can be realized with a mobile blanket; this might not be so with a fixed blanket.

In dealing with a mobile concept, it is reasonable to consider the fuel sufficiently mobile when it is circulating through the entire blanket rather than through a given "suba'ssembly" or blanket region. Further, complete mobility is the easiest mode of mobility that can be considered. The advantage of zoning a fixed blanket -- lower heat-generation rates in outer zones which permit the use of larger diameter, lower cost pins - does not exist for a zoned mobile blanket. No advantage in fabrication cost can be achieved with the mobile concepts studied, because all fuel elements will be the same size in a given blanket. A completely mobile blanket possesses at least one additional distinct advantage: burnup and plutonium build-up are distributed uniformly. over the entire blanket. This should permit the economic optimization of mobile blankets while reaching burnups of only several thousand MWD/MTU. Hence, mobile blankets should not be limited material-wise, as it was found true for fixed blanket. For these reasons, an unzoned or completely mobile concept of design is the reasonable one to use for a mobile-blanket design.

It is expected that, when comparing mobile systems with fixed systems, alloy materials will show the greatest improvement, since they were more severely limited by burnup in fixed systems. However, some improvement should be realized with oxide materials.

In this study, the basic design and the economic analysis of mobile systems were investigated. Of concern in the design were the dimensions of the blanket and its various elements. Only cursory attention was given to the problem of circulating the mobile blanket fuel material. Several methods can be used, and it is unlikely that any of them would seriously affect the design of that portion of the blanket adjacent to the reactor or seriously alter the economics for a given design.

Two representative mobile systems were selected for study. The first is a fuel system comprised of small (approximately $200 \mu$ ) fuel particles dispersed in sodium, which serves as the carrier medium but 
not as the heat transport medium. The relative proportions of fuel and sodium are such that the aggregate fluid is quite viscous and hence the name "paste" has been applied to it. Heat removal is accomplished with sodium flowing through tubes which pass through the paste bed. A sizeable effort has been devoted to paste and its rheology, and a conceptual design of a 300-Mwe paste-fueled fast reactor has been made. Details of these aspects are given in Reference 2 .

The second representative mobile system selected for study is one in which the fuel is in the form of small (approximately 1/2-in. -diameter) spheres. These spheres are placed in a slowly settling bed and heat is removed by sodium flowing through the bed. The spheres must be clad to prevent contamination of the primary coolant with fuel material and fission products, which could occur if there were intimate contact between the fuel and the sodium. This system has the advantage that it does not require a separate sodium system to transport the fuel. However, it does have certain engineering limitations that can inhibit its economic performance. This system is similar to the settled-bed concept being developed by Brookhaven National Laboratory. $(3,4)$ However, the design limitations considered in this study cause differences in the designs.

- For each system two fuel materials were considered. Uranium alloy was a common material for both mobile systems as well as for the fixed blankets. The second material for the clad-sphere system was $\mathrm{UO}_{2}$, which was the second material considered in the fixed systems. The use of $\mathrm{UO}_{2}$ in the paste system was considered, but was rejected because of the low thermal conductivity of $\mathrm{UO}_{2}$. A more suitable ceramic material in this respect is UC. Further study of UC is necessary to determine whether a problem of material compatibility would prevent its use as a paste fuel. Additional information on the thermal conductivities of $\mathrm{UO}_{2}$ paste and $\mathrm{UC}$ paste is given in Appendix. $\mathrm{I}$.

The same basic approach used in the previous phase of the study was used in this phase. Certain basic design limitations were fixed and by a combination of the disciplines of engineering, physics, and economics a blanket was designed for a reference core. When no engineering or material limitations were apparent the design was fixed as that which could optimize the economics. Brief summaries of the reference core and the blanket design limitations are given in Tables I and II.

In general, these limitations are consistent with current materials technology and good design practice. The maximum temperature limitations were established by the considerations that the temperatures must be low enough to prevent sodium boiling in the paste, low enough to prevent fission product gas release in the $\mathrm{UO}_{2}$ spheres, and low enough to prevent metallurgical decomposition of the metal alloy spheres. 
TABLE I - CORE CHARACTERISTICS

Core height, in.

Core diameter, in.

Fuel material

$\mathrm{Pu}-239 /(\mathrm{U}$ and $\mathrm{Pu}-240)$

Core volume, liters

Core power, Mwt

Core composition

$$
\text { Fuel, v/o }
$$

Coolant, v/o

Structure, v/o

Thermal efficiency, \%

Plant factor, \%

Plant life, yr

Axial blanket height (each end), in.
41.3

51.6

$\mathrm{UO}_{2}-\mathrm{PuO}_{2}$ in $\mathrm{U}-15 \mathrm{w} / \mathrm{o} \mathrm{Mo}$

9.8

1400

620

50.0

36.0

14.0

37.0

80

30

18 


\section{TABLE II - BLANKET DESIGN LIMITATIONS}

Blanket height, in.

76.8

Coolant inlet temperature, F

Alloy fuel material

500

Ceramic fuel material

700

Coolant temperature rise, $F$ 500

Pressure drop, psi

Maximum temperature, $F$

Paste (carbide)

1200

Paste (metal)

1150

Metal sphere, center

1150

$\mathrm{UO}_{2}$ sphere, center

1600 
Since the basic approach is the same as used in Reference 1 , special attention is given in subsequent portions of the report to those areas that are different. Specifically, they are the batch concept for mobile fuel, engineering analysis of mobile systems, and mobile blanket fabrication costs. 


\section{BATCH -MOBILE -FUEL -MANAGEMENT CONCEPT}

One of the inherent potential advantages of a mobile fuel system for blanket application is that of obtaining high average fuel utilization or fuel burnup. Fixed blanket elements, because of the spatial distribution of neutron flux, have high maximum-to-average flux ratios and, since element design is based on mechanical integrity, these elements are usually removed from the reactor when the location of maximum flux achieves a metallurgically limited burnup. The resulting high maximum-to-average burnup greatly reduces the over-all utilization of this type of blanket fuel. A mobile fuel blanket, however, by in-reactor motion, overcomes adverse flux distribution by continually altering the spatial location of each fuel module. This allows each fuel module to attain a more uniform exposure and resulting higher fuel burnup.

Limiting considerations for maximizing uniform flux exposure are the ability to achieve thorough fuel module mixing and the ability to determine the extent of fuel burnup. Both requirements are satisfied with a mobile system. For example, consider the case of a blanket comprised of stainless steel-clad $\mathrm{UO}_{2}$ spheres which make up a slowly settling fuel column cooled by up-flowing sodium. These fuel spheres are introduced at the top of the blanket container assembly through a loading tube that penetrates the reactor vessel. They then settle downward through the core, and at the bottom, go into an inlet port of a lifting device which moves them upward and, either back in the blanket region for further exposure, or out of the reactor vessel for burnup analysis. An approach to the maximum fuel burnup level can be made by use of statistical sampling, and by maintaining a proper relation between the fuel-sphere diameter and characteristic dimension of the fuel-container assembly, which tends to insure a random arrangement of this fuel. This, however, is definitely a batch process, that is, one in which a blanket fuel loading is introduced, circulated to removal burnup, and then replaced with a subsequent fuel charge. 


\section{ENGINEERING ANALYSIS}

\section{PASTE BLANKET}

A detailed description of proposed mobile core and mobile blanket subassemblies is given in Reference 2. Because of the thoroughness of the document, little can be gained by a radical departure from the design approach and resulting configuration presented therein. To maintain continuity throughout the blanket study, the ground rules imposed on the fixed blanket design will be applied to the mobile systems and the presented design configurations altered to suit these requirements.

By way of summary, the paste-blanket element of Reference 2 is a shell-and-tube heat exchanger in a hexagonal shape with tapered ends leading to single paste inlets and outlets on the side. The heat-transport system consists of sodium flowing through the tube side. The tubes are arranged on a triangular pitch and the ligaments between them vary inversely with the volumetric heat generation radially outward from the axial centerline of the core. The number and size of the tubes are determined by heat load, blanket temperature rise, allowable pressure drop and desired volume composition. The maximum paste temperature (excluding a $50 \%$ power-override factor, which would be desirable, and hot-channel factors) is limited to $1150 \mathrm{~F}$ due to the metallurgical limitations of the dispersed phase (sintering temperature of uranium metal) and the boiling point of the continuous phase sodium. If stainless steel is selected as the structural material, the maximum temperature will of necessity be reduced, due to a potential eutectic formation between uranium and iron.

As was true with the fixed-blanket design, the desired end product is a graphical representation of volumetric heat generation as a function of blanket composition. With the maximum allowable fuel temperature fixed at $1500 \mathrm{~F}$ and the geometry established (cooling tubes on a triangular pitch), a fixed relationship between tube pitch, tube diameter, and volumetric heat generation arises. Further, since volume composition is closely related to tube pitch and tube diameter, the desired geometric relation to composition arises. Such a graphical representation is shown in Figure l. Essentially the same considerations assumed for the fixed blanket have been assumed here as listed below:

1. Maximum fuel temperature - $1500 \mathrm{~F}$ with $50 \%$ power override factor 


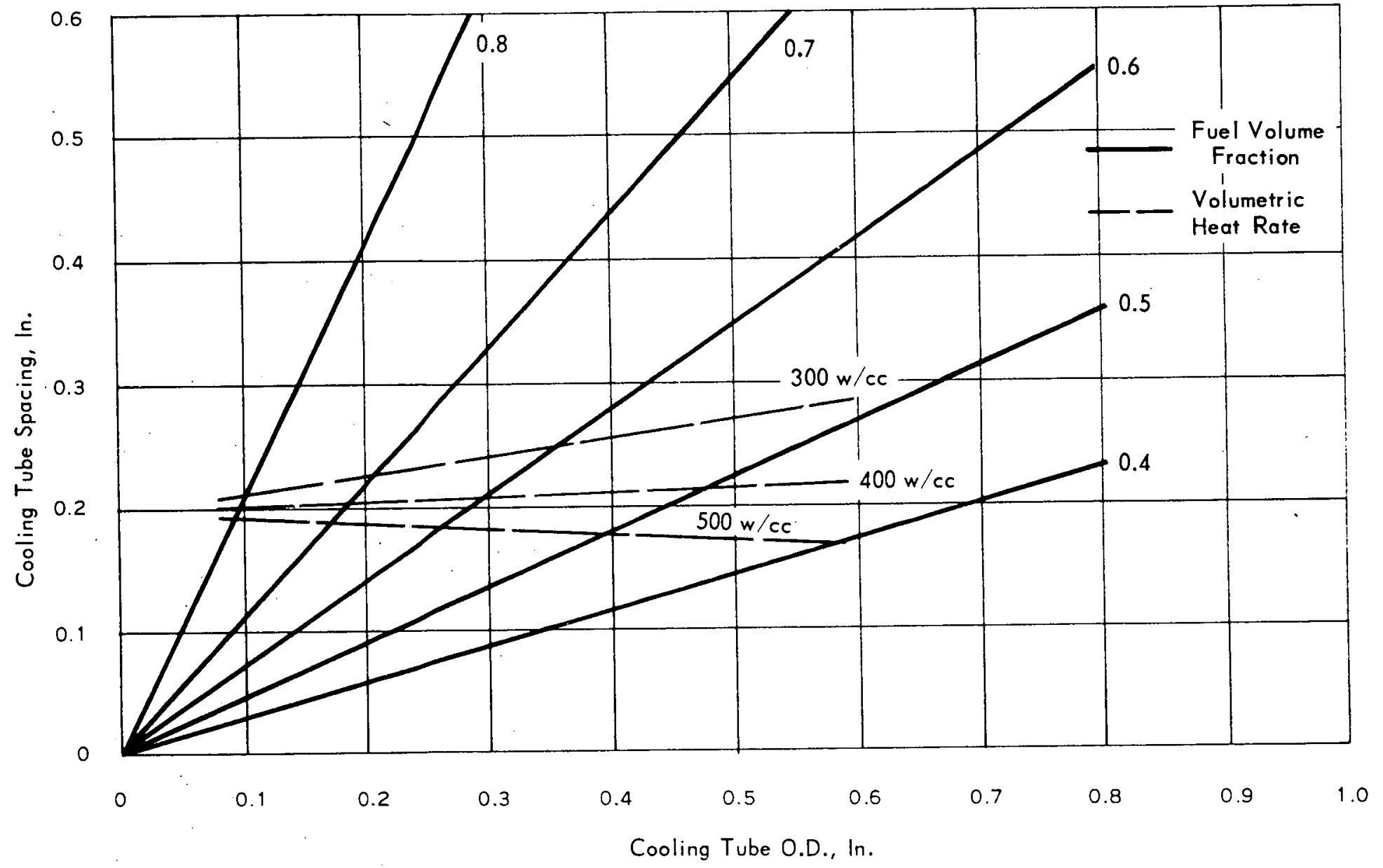

FIG. I OUTSIDE DIAMETER AND SPACING OF COOLING TUBES FOR PASTE CONCEPT 
2. Temperature at blanket inlet and maximum temperature rise - both $500 \mathrm{~F}$ respectively

3. Pressure drop in blanket - 50 psi

4. Geometry of cooling tubes - triangular pitch

5. Wall thickness of coolant tubes - 0.015 inch

6. Height of blanket -76.8 inches

In this figure, one family of lines is the result of geometry considerations; the second family of lines is the result of the temperature limitations, with the heat generation rate as a parameter. These curves are valid for $\mathrm{U}-3 \mathrm{w} / \mathrm{o}$ Mo alloy paste as well as for UC paste since both have nearly the same thermal conductivity.

\section{CLAD -SPHERE BLANKET}

This alternate design consists of metal-clad fuel spheres arranged in a slowly settling packed bed. The blanket height is 76.8 inches, and the allowable pressure drop is 50 psi. Blanket inlet temperatures and sodium coolant temperature rise are, as in other designs, $700 \mathrm{~F}(500 \mathrm{~F}$ for metallic fuels) and $500 \mathrm{~F}$, respectively. The anticipated burnup for the clad-sphere blanket is low; thus, the amount of fission gas produced will be small. Consequently, the cladding of the sphere need not be considered to be a pressure vessel but as merely a barrier between the fuel and coolant, capable of withstanding a small amount of radiation-induced strain and thermal effects. The cladding, then, can be thin. Thermal loading is determined by using the following equation for fuel temperatures.

$$
\begin{aligned}
\mathrm{T}_{\mathrm{f}} & =\frac{\mathrm{q}^{\prime \prime \prime} \mathrm{r}_{\mathrm{f}}^{2}}{6}\left[\frac{1}{\mathrm{k}_{\mathrm{f}}}+\frac{2}{\mathrm{r}_{\mathrm{f}} \mathrm{h}_{\text {gap }}}+\frac{2 \mathrm{r}_{\mathrm{f}}}{\mathrm{k}_{\mathrm{c}}} \frac{\mathrm{t}}{\mathrm{P}_{\mathrm{c}} \mathrm{r}_{\mathrm{f}}}+\frac{{ }^{2 \mathrm{r}_{\mathrm{f}}}}{\mathrm{r}_{\mathrm{C}}{ }^{2} \mathrm{~h}_{\mathrm{film}}}\right] \Delta \mathrm{t} \text { coolant }+\mathrm{T}_{\text {inlet }} \\
\text { where } \mathrm{q}^{\prime \prime \prime} & =\text { volumetric heat generation } \\
\mathrm{r}_{\mathrm{f}} & =\text { fuel radius } \\
\mathrm{r}_{\mathrm{c}} & =\text { cladding radius } \\
\mathrm{k}_{\mathrm{f}} & =\text { fuel conductivity } \\
\mathrm{k}_{\mathrm{c}} & =\text { cladding conductivity }
\end{aligned}
$$




$$
\begin{aligned}
& h_{\text {gap }}=\text { gap conductance } \\
& h_{\text {film }}=\text { film conductance } \\
& P_{C}=\text { fuel rod perimeter } \\
& T_{f}=\text { fuel center temperature } \\
& t \quad=\text { cladding thickness }
\end{aligned}
$$

The heat transfer coefficient, $h_{f}$ is quite small, and, since information on settled bed systems is limited, an equation for water systems was used. It is felt that this approach is quite conservative. A suitable correlation is Kramer's equation, from which the film coefficient for beds packed with spheres is determined as follows:

$$
\frac{h_{f} D_{P}}{k}=2.0+1.3 \mathrm{~N}_{\operatorname{Pr}}^{0.15}+0.66 \mathrm{~N}_{\operatorname{Pr}}^{0.31} \mathrm{~N}_{\mathrm{Re}}{ }^{0.5}
$$

where $D_{P}=$ particle diameter

$\mathrm{k}=$ thermal conductivity of fluid

$h_{f}=$ convective film temperature coefficient

The other remaining correlation used, which introduced the pressure drop limitation, is that set forth by Burke and Plummer for flow through beds packed with spheres:

$$
\Delta P=\left(3.50 \frac{1}{D_{P}} \cdot \frac{1}{2} V_{0}^{2} \frac{1-E}{E^{3}}\right) \quad L
$$

where $V_{0}=$ superficial fluid velocity through on empty bed

E. = fractional porosity.

$L \quad=$ bed length

In order to establish the proper value for the fractional porosity, the experimental information presented in Reference 5 was used. These data, shown in Figure 2, were introduced into the pressure drop correlation to establish the region of allowable sphere diameters and heat generation 


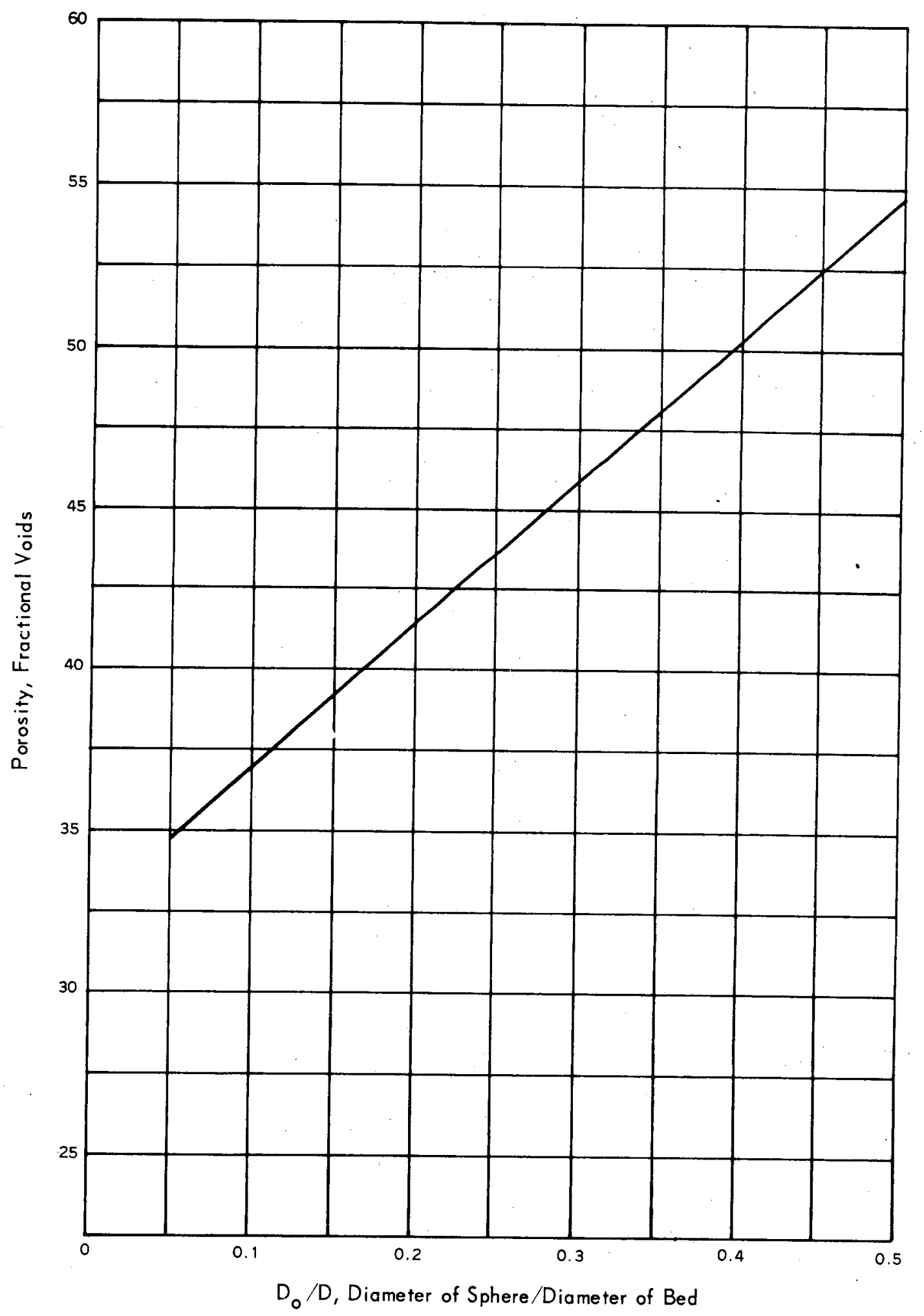

FIG. 2 POROSITY AS A FUNCTION OF THE RATIO OF SPHERE DIAMETER TO BED DIAMETER 
rates consistent with a pressure drop of $50 \mathrm{psi}$. This curve is given in Figure 3. The thermal loading equation was used to establish a similar relation - - one which would produce center temperatures consistent with design limitations. This relationship is also given in Figure 3. The intersection of the thermal loading curve and the pressure drop curve determines uniquely the sphere diameter and the end-of-life maximum heat-generation rate.

It should be noted that the combined limitations of temperature and pressure drop impose a severe restriction on the clad-sphere concept. They permit relatively low heat-generation rates which, as will be shown later in this report, limit the lifetime and the profit potential of a blanket using this concept. These limitations can be expected because a bed of packed spheres has a very high pressure drop per unit length, compared with a bed with the coolant flowing through unrestricted tubes. In contrast, the pressure drop limitation does not cause any serious problem with the paste concept. For the heat generation rates of interest, the pressure drop limitation occurs for coolant tube diameters that are much smaller than those of practical interest. For example, it is not practical to consider coolant tube diameters of much less than 0.25 inch and the pressure limitation is not reached until the tube diameter is decreased to about 0.1 inch.

\section{CIR CULATION SYSTEM}

Since it is assumed that the blanket fuel material for the mobile systems will be circulated, a system to achieve this must be considered. The depth of this study does not permit a detailed investigation of this aspect of mobile blankets, but it is not anticipated to be a major problem. Among the reasons for this optimistic attitude is the low circulation rate required to achieve uniform burnup and plutonium buildup of the blanket material. As will be demonstrated later in this report, the optimum lifetime for mobile blankets is about 3 to 5 years. Consequently, it would probably be sufficient for blanket fuel to pass through the blanket at a rate no greater than once a day.

Actually, a circulatory system was designed for the paste concept. (2) The basic feasibility of the system has been established, but has not been verified by test. For the clad-sphere concept, circulation of the spheres external to the blanket could be accomplished by either a positive lift device, such as a large rotating screw or an elevator mechanism, or by lifting the spheres in a high-velocity sodium stream. 


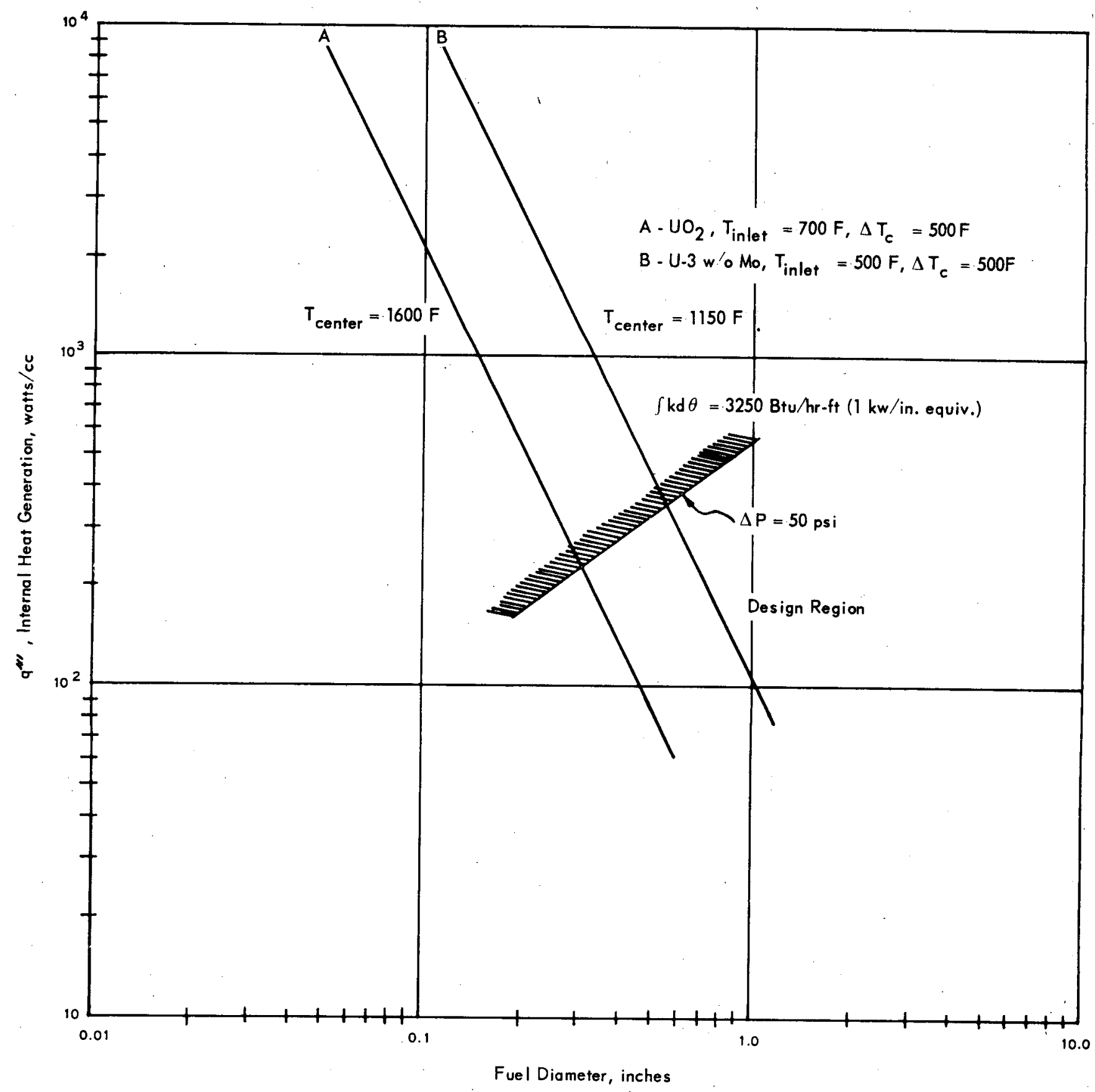

FIG. 3 INTERNAL HEAT GENERATION OF BLANKET SPHERE AND DIAMETER OF FUEL SPHERE 
FABRICATION COSTS OF MOBILE BLANKETS

\section{PASTE MATERIALS}

The commercial preparation of spherical U-Mo alloy and UC powders has not reached the stage where reasonable cost data is available. Various techniques for preparing these powders have either been proposed or have undergone some development, $(6,7,8)$ but the scope of work does not easily lead to an extrapolation of development costs to production costs.

In the production of elemental and alloy powders, the ferrous and nonferrous metals industry routinely employs such techniques as electrochemical reduction, shotting, and atomization. These operations indicate that costs, exclusive of the intrinsic value of the powder, are generally proportional to the complexities associated with each fabrication technique and to the quality, chemical purity, particle size and shape specified by the customer. Some metals are inherently more difficult to produce in powder form than others; for example, their melting points might be quite high or their chemical activity might require handling in an inert atmosphere or vacuum. Also, the process characteristics and physical properties (e.g., surface tension) of the particular metal may produce a preponderance of undesirable particle sizes, either too small or too large. The foregoing are not necessarily prohibitive cost items but they have a definite effect on the cost of the ultimate product.

Where a market exists for tonnage quantities of metal powders, prices are usually competitive, assuming the existence of a "buyer's market." The market price, therefore, is influenced by demand as well as by competition. The uranium products market at the present time is limited; there are few fabricators in the business, and these are highly specialized. There is no tonnage market for uranium metal powder in the same sense as there is for ferrous metal powders, nor is it likely that there ever will be. Presently, the capacity for production is geared to the infrequent demands for reactor fuel and blanket materials, and the term "production quantities" is most generally applied only to the relatively simple shapes found in pressed and sintered $\mathrm{UO}_{2}$, which, when used in a commercial power reactor, requires a large number of individual pellets.

Cost estimating for U-Mo alloy and UC spherical powders is definitely an arbitrary process. Where there is no market, there obviously is no reliable cost information; opinions, or educated guesses, obtained informally from several vendors covered a broad range of 
costs as influenced by their own individual experience. This experience, typically, has been with the type of equipment and processing batches generally associated with enriched fuel materials. It is assumed here that, in time, it will be possible to produce volume quantities of depleted blanket materials by similar techniques without a cost penalty. Improvements in equipment and processing techniques would, hopefully, be expected to increase powder yields and throughputs with resultant lower costs.

Assumed; as-delivered costs for depleted U-Mo and UC spherical powders are as follows:

$$
\begin{array}{ll}
\mathrm{U}-\mathrm{Mo}_{0}(\sim 200 \mu) & \$ 15-30 / \mathrm{Kg} \mathrm{U} \\
\mathrm{UC} \quad(\sim 200 \mu) & \$ 10-20 / \mathrm{Kg} \mathrm{U}
\end{array}
$$

These costs include the uranium, with a value of $\$ 3 / \mathrm{Kg} \mathrm{U}$ as $\mathrm{UF}_{6}$, a direct purchase item. The powder vendor would either purchase the ${ }^{6}$ depleted $U_{6} 6$ directly from the AEC and do his own conversion, or would buy his starting material (uranium-metal for the U-Mo powder, $\mathrm{UO}_{2}$ for UC powder) from a converter. In any case, the cost to the reactor operator would be the same. It is also as sumed that the U-Mo powder would be made by the spinning disk method $(6,7)$, atomizing method $(6)$, or by the drop-shot method (9). The feasibility of any of these three methods is not questioned; it is simply assumed that these methods are typical and are applicable.

It is surmized that the UC powder will be produced by the plasma torch method, the feasibility of which has been demonstrated(7). For both types of powder, the base price is predicated on an order of at least $20,000 \mathrm{Kg}$ of powder. This is an arbitrary amount picked solely as the minimum quantity that a potential vendor, one of those previously referred to, would associate with a dollar price range.

\section{SETTLED-BED MATERIALS}

The large particle size of the two settled-bed materials 10.55 inch-diameter for $\mathrm{U}-3 \mathrm{w} / \mathrm{o}$ Mo and 0.30-inch-diameter for $\mathrm{UO}_{2}$ ) essentially limits their fabrication to such techniques as casting or forging of the metallic U-3 w/o Mo; and pressing and sintering, or slip casting and sintering, of the ceramic $\mathrm{UO}_{2}$. Metal coating of the U-3 w/o Mo and $\mathrm{UO}_{2}$ spheres with a metal such as niobium, tungeten, or zirconium may be possible by the vapor deposition method (metal halide reduction) and by hydrostatic or gas-pressure bonding of pre-formed cladding hemispheres of appropriate thickness.

The fact that U-Mo alloys, specifically U-3 w/o Mo and U-10 w/o Mo, can be fabricated has been reasonably demonstrated during manufacture of the core and blanket for the Fermi reactor, the first core for the Sodium -20 - 
Graphite Reactor, and the core for the Dounreay Reactor. And, there is no reason to doubt that spheres of depleted $\mathrm{U}-3 \mathrm{w} / \mathrm{o}$ Mo, approximately $1 / 2$-inch in diameter, can be made, in quantity, by either casting or hot forging. For either process, the alloy would probably be prepared by induction-vacuum-melting and then cast into ingots to be either used as melt stock for the casting process or extruded into rod stock for the forging process. Forging is a particularly attractive process if techniques like those used in the ball-bearing industry are applicable. Here, automatic forging presses are employed which pre-heat rod stock; shear the heated rod into small slugs as it is fed into the press; then feedand orient the slugs into the die cavity, where they are forged into spheres. The forged spheres have a slight circumferential irregularity which is removed by grinding. It may be possible to produce volume quantities of $U-3$ w/o Mo spheres, especially depleted material, at reasonable cost in a similar manner.

Powder metallurgy must be employed to fabricate spheres approximately $1 / 2$-inch in diameter from ceramic $\mathrm{UO}_{2}$. In this case conventional cold pressing of the powder seems applicable. Also, a slip-casting technique for making $\mathrm{UO}_{2}$ spheres has been used successfully by the Hanford Laboratories $(10)$.

Coating of the relatively large diameter $\mathrm{U}-3 \mathrm{w} / \mathrm{o}$ Mo and $\mathrm{UO}_{2}$ spheres with approximately 12 mils of metal cladding is yet another problem which, as a first approach, might be resolved by applying and modifying techniques used for coating small diameter (approximately $200 \mu$ ) $\mathrm{UO}_{2}$ and $\mathrm{UC}$. The literature is rather extensive on metal-coated ceramic particles as nuclear fuel materials and there is obvious impetus by several fuel vendors to apply AEC-sponsored work as well as their own to commercial applications.

\section{SUMMARY}

The paste and settled-bed blanket materials are tabulated below in order of increasing fabrication cost. These figures are estimates predicated on the assumed fabrication techniques mentioned earlier in this section of the report.

\section{Material-Form}

1. UC spherical powder $\left(\sim 200_{\mu}\right)$

2. U-3 w/o Mo spherical powder $(\sim 200 \mu)$

\section{$\underline{\operatorname{Cost}(\$ / \mathrm{kg} U)}$}

$10-20$

$15-30$

3. $\mathrm{UO}_{2}(1 / 2$-inch spheres with $12-$ mil cladding of $\mathrm{Nb}, W$, or $\mathrm{Zr}$ )
$20-40$ 
4. U-3 w/o Mo (1/2 -inch spheres with 12 -mil cladding of $\mathrm{Nb}, \mathrm{W}$, or $\mathrm{Zr}$ )

Two other items must be considered as contributions to fabrication cost. One of these is the sodium carrier in the paste; the other is the container system for the mobile blanket material.

The price of the carrier medium, sodium, has little impact on the over-all cost picture. Assuming a base price of $20 \xi / 1 b$ for sodium and prorating this expense over the mass of uranium adds only about $5 \xi / \mathrm{kg} \mathrm{U}$.

The container system for the clad-sphere concept would be a simple, low - cost annular vessel, with interior walls that serve as annular and radial spacers to achieve the desired porosity. Such a container, due to its comparatively low cost and long lifetime, need not be included either in the fabrication cost of the clad spheres or at any point in the economic analysis. The container system for the paste concept is a shell-and-tube, heat-exchanger or radiator-type structure. It is expected that such a container would be costly and difficult to build and that it would have a relatively short lifetime. In order to arrive at a cost estimate, the mass of the structural material in the paste blanket design was costed on a dollars-per-pound basis at the same rate used for core subassembly hardware in the Fermi reactor. Proration of this value over the amount of uranium in the paste blanket yielded an estimated container cost of $\$ 10 / \mathrm{kg}$ U. This amount must be added to the fabrication costs of the paste material given in the preceding tabulation. The total fabrication costs, then, are:

Material-Form

1. UC spherical powder $(\sim 200 \mu)$

2. U-3 w/o Mo spherical powder $(\sim 200 \mu)$ $25-35$

3. $\mathrm{UO}_{2}(1 / 2$-inch spheres with $12-\mathrm{mil}$ cladding of $\mathrm{Nb}, \mathrm{W}$, or $\mathrm{Zr}$ )

$20-40$

4. U-3 w/o Mo (1/2-inch spheres with 12 -mil cladding of $\mathrm{Nb}, \mathrm{W}$, or $\mathrm{Zr}$ ) $30-60$

Recycling expenses and scrap losses, as influenced by a narrow range of acceptable final sizes, may make U-3 w/o Mo and UC spherical powders the most costly of the several particulate materials to fabricate. 
But they may be the easiest to produce. The summary of assumed fabrication processes presented in Appendix II shows the major differences in these techniques and their influence on total fuel costs.

All the fabrication techniques discussed in Appendix II are feasible and reflect comments and opinions of both vendors and those engaged in fuel fabrication studies. The above-tabulated cost estimates are, by industrial standards, definitely on the low side. And justifiably so. Present day experience is limited almost entirely to enriched uranium fuels (natural uranium to a lesser degree) with such associated limitations as process throughputs and scrap losses. It is unnatural to make high cost estimates on a product not yet commercially available when there is a compelling reason to do otherwise; the compelling reason here is to put the relatively simple forms of paste and settled-bed blanket materials into their proper perspective. These materials should not be penalized by arbitrary high costs, comparable to those for enriched fuels, just because they have no present market. 


\section{ECONOMIC ANALYSIS}

The method of economic analysis employed in this study was the same one developed for and used in the study of fixed blankets; also, the economic data used was basically the same. (1) Specifically, the price of uranium, the cost of reprocessing and the price of heat were left unchanged. The cost of plutonium was fixed at $\$ 10 / \mathrm{gm}$ and the interest rate at $13 \%$. These latter values are nominal and will be consistent with the economic climate for some time to come.

From the preceding section it is clear that the fabrication costs for mobile systems are, at present, difficult to determine. In order to treat this problem properly, three values of fabrication cost were used, viz., $\$ 15, \$ 30$, and $\$ 60 / \mathrm{kg}$ of uranium. These values represent the estimated low, medium, and high prices for fabrication. Thus, with three cost estimates being used with two fuel materials in combination with two fuel systems, a total of twelve economically optimum blanket designs were contrived. 


\section{PHYSICS ANALYSIS}

Using the analytical method previously developed, (1) representative mobile cores were studied with multigroup diffusion theory to obtain representative reaction rates. The economic analysis method, also previously developed, was then used to determine the achievable profit and blanket lifetime for each system. This process was repeated in an iterative fashion to determine the reaction rates that were representative averages over the blanket lifetime, taking into account spectrum changes due to plutonium production. For both mobile blanket concepts it was necessary to extend this iterative process with thickness of the blanket as another parameter. Thus, the optimum blanket thickness could be determined. In addition, for the paste concept, it was necessary to include the radial distribution function for the volume fraction of paste in the blanket as a variable in the iteration and optimization process. This can be done because both the diameter and pitch of the coolant tube can be varied with radial position. The diameter of the coolant tube for each system studied was fixed for the entire blanket at that value required at the inner edge of the blanket, and the pitch was varied in such a way as to make the paste volume fraction be linear across the blanket. These two variables were then included in the design optimization study.

No such extension of the iteration process was necessary for the clad-sphere systems. The composition of these systems is defined by the physical consideration of the relative amounts of coolant, structural material, and fuel that can be placed in a bed of randomly packed spheres.

It was found that for any given plutonium concentration the spectrum was sufficiently uniform over the blankets to allow average reaction rates for a blanket to be determined by simple volume averaging.

From the results of the study it was found that there is a correlation between certain reaction rates and the results of the economic analysis. Details are given in Appendix III. By use of this relationship, it is possible to determine qualitatively the relative economic potentials of blankets under consideration by examination of their reaction rates: 


\section{SUMMARY OF RESULTS}

The results of the design optimization studies on mobile systems are presented in Tables III through VII. These results indicate that the paste system will reach, or nearly reach, optimum when the paste volume fraction is 0.45 at the inner edge of the blanket and increases at the rate of 0.01 per $\mathrm{cm}$ of radius. Also, the results of a preliminary study of paste systems indicate that a lumped blanket has a slightly higher profit potential than a zoned blanket. By definition, a lumped blanket is one in which the paste circulates and mixes through the entire blanket; a zoned blanket is one in which the paste circulates and mixes within its particular blanket region, but not with the paste of other regions. Since lumped paste systems are the simplest and most economical to build and operate, the remainder of the study was devoted to them. Inasmuch as the paste concept, as outlined in Reference 1, requires the paste to be contained within distinct subassemblies, a typical subassembly thickness of $10 \mathrm{~cm}$ was considered to be the radius increment for the paste blanket study.

It should be noted that for the clad-sphere designs, the terminal burnup is only on the order of $1000 \mathrm{MWD} / \mathrm{MTU}$ and for the paste designs it is only 2000 to $4000 \mathrm{MWD} / \mathrm{MTU}$. Such low burnups are the result of the circulation of the blanket fuel and are necessary for achievement of maximum profits. It is, therefore, doubtful that there would be any advantage in the use of a process whereby fuel would be continuously remaved and reprocessed on-site upon meeting a criterion related to burnup and buildup. The batch concept undoubtedly would be more economical for these blanket situations.

The total mass of uranium in the mobile blanket designs is about 20 metric tons for most of the paste systems and for the low-and mediumcost $\mathrm{UO}_{2}$ sphere systems. It was found that profit is not very sensitive to blanket thickness where sphere systems are concerned. Therefore, the uranium masses given for the sphere-blanket designs are rather rough values. In an economic sense, the amount of uranium contained in the optimum blanket remains the same regardless of the blanket concept or the fuel material.

In addition, the breeding ratio for the blanket of optimum thickness is only weakly dependent on the blanket concept and blanket fuel material.

The method used to determine the lifetime for a system can be best described through the use of Figure 4. The profit and the maximum end-of-life heat generation rate for the $\mathrm{UO}_{2}$ sphere concept were 
TABLE III - SUMMARY OF RESULTS FOR

CLAD-SPHERE BLANKETS

\begin{tabular}{|c|c|c|c|c|c|c|}
\hline Type & $\begin{array}{c}\text { Fabrication } \\
\text { Cost } \\
(\$ / \mathrm{kgU}) \\
\end{array}$ & $\begin{array}{c}\text { Lifetime } \\
(\mathrm{y} r) \\
\end{array}$ & $\begin{array}{c}\text { Terminal } \\
\text { Buildup } \\
\% \\
\end{array}$ & $\begin{array}{c}\begin{array}{c}\text { Terminal } \\
\text { Burnup }\end{array} \\
\text { (MWD/MTU) } \\
\end{array}$ & $\begin{array}{c}\text { Total } \\
\text { Profit } \\
(\$ / y r) \\
\end{array}$ & $\begin{array}{c}\text { Ball } \\
\text { Diameter } \\
\text { (in.) } \\
\end{array}$ \\
\hline Alloy & 15 & 2.9 & 0.87 & 850 & 330,000 & 0.55 \\
\hline Alloy & 30 & 2.9 & 0.87 & 850 & 170,000 & 0.55 \\
\hline Oxide & 15 & 3.4 & 1.30 & 1130 & 410,000 & 0.30 \\
\hline Oxide & 30 & 3.4 & 1.30 & 1130 & 300,000 & 0.30 \\
\hline Oxide & 60 & 2.9 & 1.30 & 1260 & 100,000 & 0.30 \\
\hline
\end{tabular}


TABLE IV - PHYSICS DATA FOR

\section{CLAD_SPHERE SYSTEMS}

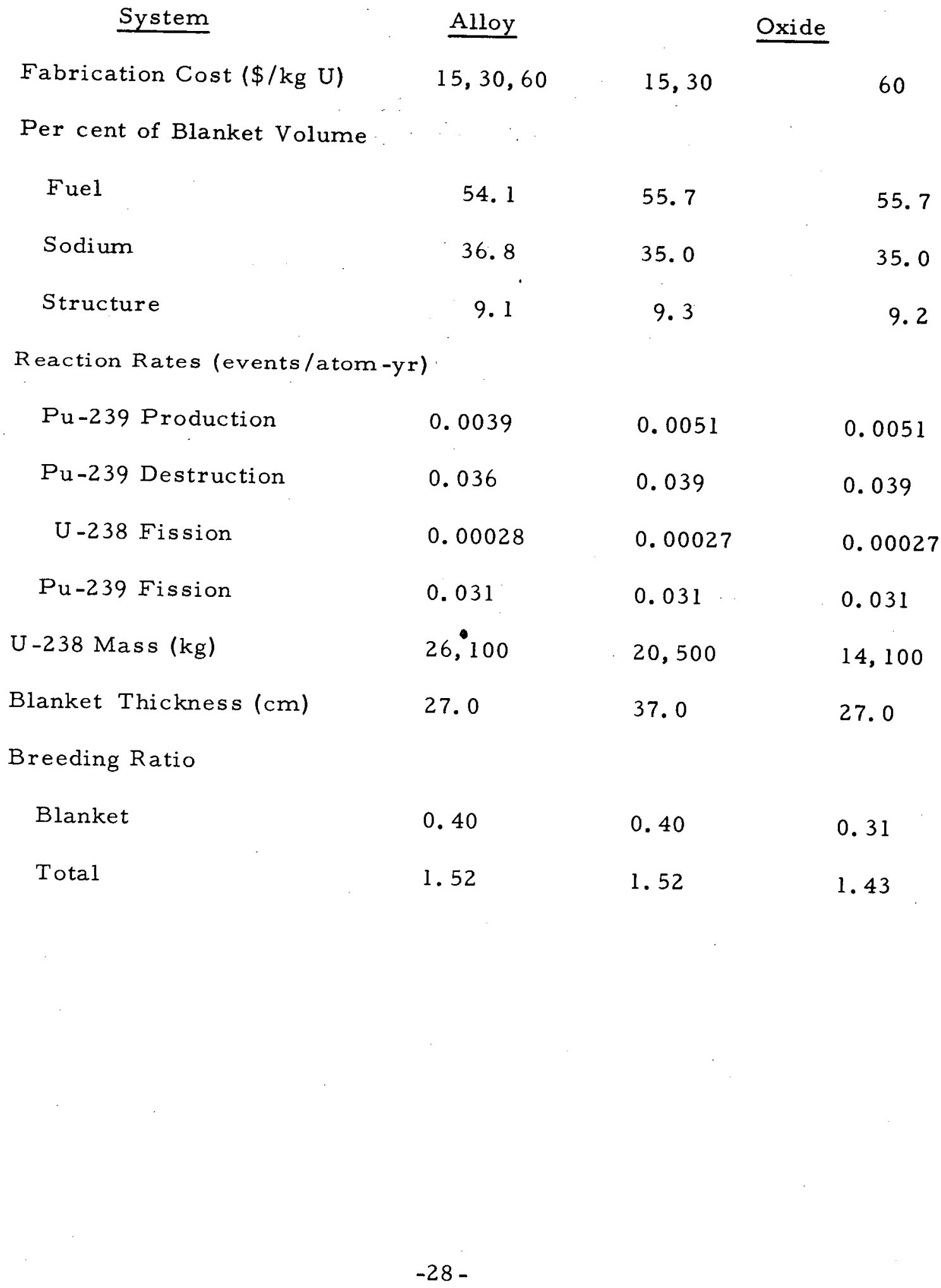




\section{TABLE V - SUMMARY OF RESULTS FOR PASTE SYSTEMS}

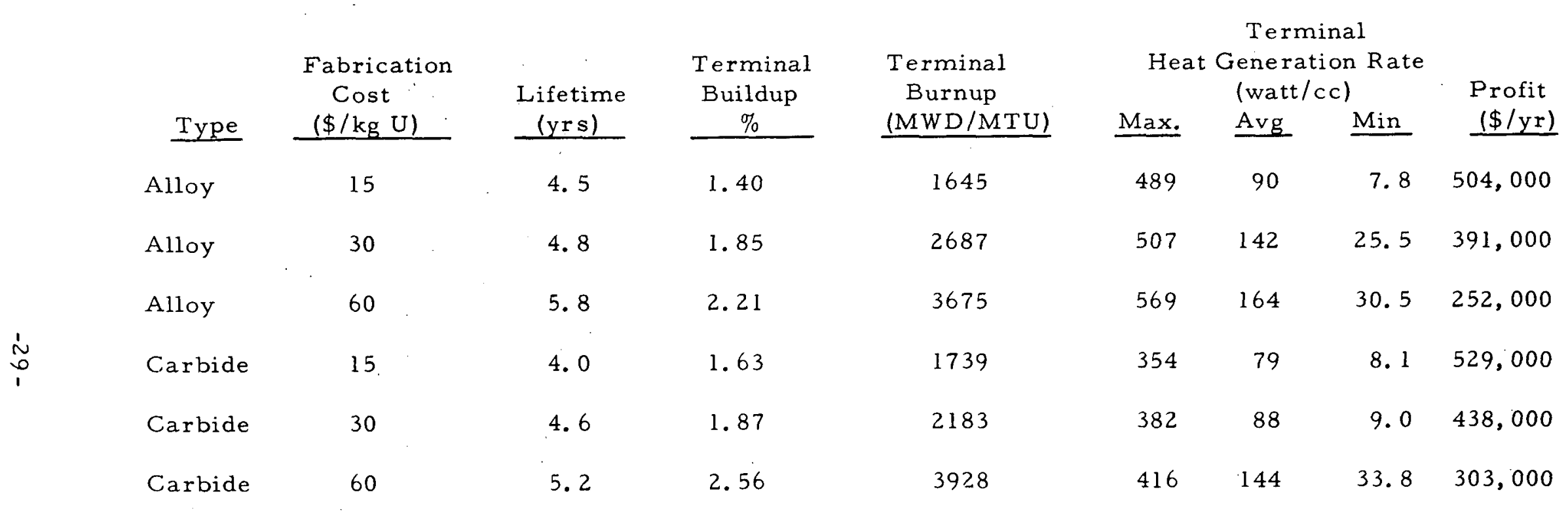


TABLE VI - ENGINEERING DESIGN DATA FOR PASTE SYSTEMS

\begin{tabular}{|c|c|c|c|c|c|}
\hline Type & $\begin{array}{c}\text { Fabrication } \\
\text { Cost } \\
(\$ / \mathrm{kg} \mathrm{U}) \\
\end{array}$ & $\begin{array}{c}\text { Blanket } \\
\text { Thickness } \\
(\mathrm{cm}) \\
\end{array}$ & $\begin{array}{c}\text { Total } \\
\text { mass of } \\
\text { U-238 } \\
(\mathrm{kg}) \\
\end{array}$ & $\begin{array}{c}\text { Coolant } \\
\text { Tube } \\
\text { Diameter } \\
\text { (in.) } \\
\end{array}$ & $\begin{array}{c}\text { Minimum } \\
\text { Coolant } \\
\text { Tube Spacing } \\
\text { (in.) } \\
\end{array}$ \\
\hline Alloy & 15 & 40 & 29.520 & 0.51 & 0.19 \\
\hline Alloy & 30 & 30 & 19,080 & 0.48 & 0.17 \\
\hline Alloy & 60 & 30 & 19,080 & 0.45 & 0.16 \\
\hline Carbide & 15 & 40 & 21,720 & 0.70 & 0.25 \\
\hline Carbide & 30 & 40 & 21,720 & 0.60 & 0.23 \\
\hline Carbide & 60 & 30 & 14,040 & 0.58 & 0.21 \\
\hline
\end{tabular}




\section{TABLE VII - PHYSICS DATA FOR PASTE SYSTEMS}

\section{Fabrication}

Cost

Type

$(\$ / \mathrm{kg} U)$

\begin{tabular}{lll} 
& Alloy & 15 \\
& Alloy & 30 \\
& Alloy & 60 \\
$\stackrel{\omega}{\omega}$ & Carbide & 15 \\
\hline & Carbide & 30 \\
& Carbide & 60
\end{tabular}

\begin{tabular}{|c|c|c|c|}
\hline$P u-239$ & $P u-239$ & $U-238$ & $\mathrm{Pu}-239$ \\
\hline Production & Destruction & Fission & Fission \\
\hline
\end{tabular}

0.00416

0.00526

0.00531

0.00544

0.00548

0.00689
0.0361

0.0462

0.0469

0.0423

0.0427

0.0545
0.000296

0.000416

0.000437

0.000330

0.000340

, 0.000477
0.0305

0.0391

0.0397

0.0339

0.0343

0.0441

\section{Breeding Ratio} Blanket Total
0.43
1.55

0.37

1. 49

0.37

1. 49

0.41

1. 53

0.41

1.53

0.35

1. 47 


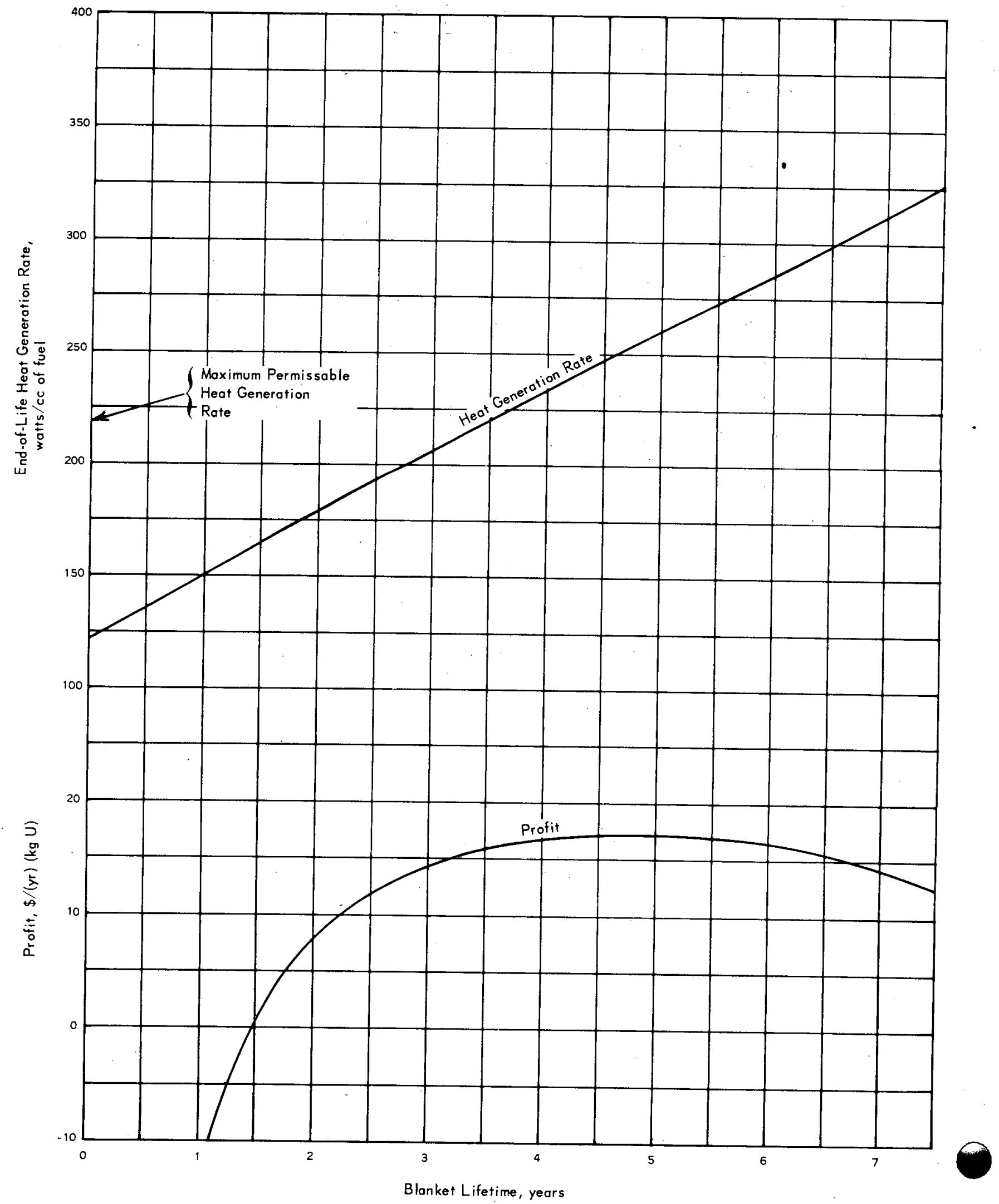

FIG. 4 PROFIT AND END-OF-LIFE HEAT GENERATION RATE FOR UO 2 SPHERE BLANKET 
calculated as a function of lifetime for lifetimes from 0.1 year to 7 years in increments of 0.1 year. From the results plotted in Figure 4 it can be observed that the proper lifetime is determined to be the life time when the limiting heat-generation rate occurs. The lifetime is selected in this way for the example discussed because the lifetime at which the limiting heat-generation rate occurs is shorter than the lifetime for which profits are maximized. For the paste concepts, there is no limit on the heat generation rate. Consequently, it is possible to select the paste blanket lifetime as that at which profits are maximized. 


\section{COMPARISON OF MOBILE SYSTEMS}

The profit for each mobile system is plotted as a function of fabrication cost in Figure 5. From the results presented above it is apparent that, for any given fabrication cost, the paste blanket is substantially more profitable than the blanket of clad spheres. In addition, for either system, the blanket of ceramic material is more profitable than the one of uranium alloy, for any given fabrication cost. The basic cause of these differences is the spectrum. The oxygen or carbon in the ceramic material and the carrier sodium in the paste provide sufficient spectral softening to cause the reaction rates to be enhanced. This can be seen by comparing the production-rate-todestruction-rate ratios of plutonium; uranium-alloy materials exhibit lower values than ceramic materials, and clad-sphere systems have lower values than paste systems.

The effect of spectral softening on the economics of a system might be pursued to the point of considering a thermalized blanket. However, there may be a limit to the amount that this effect will enhance the profit of the system. Studies in Reference 11 indicate little economic advantage of a blanket containing large amounts of graphite over one without graphite. Another cause for difference between profit of the cladsphere systems and that of the paste systems is the engineering limitation on the heat-generation rate in the clad-sphere systems. This limitation, being a result of the ground rules that were imposed, has a very strong effect on the profits of the clad-sphere systems. In contrast, the paste system is not limited economically by any engineering or materials limitations that can be linked to blanket lifetime.

The economic advantage of the ceramic systems over the alloy systems probably would be enhanced if realistic fabrication costs were used. Although true cost data is not available, it is expected that ceramic spheres will be cheaper than alloy spheres, that ceramic paste will be cheaper than alloy paste, and that paste of a given material will be cheaper than spheres of the same or similar material. Thus, for the systems studied, paste systems in general will be far more profitable than sphere systems. In addition, the profit of a system using ceramic material will be greater than that of the same system using alloy material. It is doubted that the changes in fabrication costs would ever be large enough to cause any given system to be more profitable for an alloy material than for a ceramic material, within the limits of the systems and materials considered in this study.

The profit difference between paste and clad-sphere systems is on the order of $\$ 100,000$ to $\$ 200,000$ per year. This difference is equivalent 


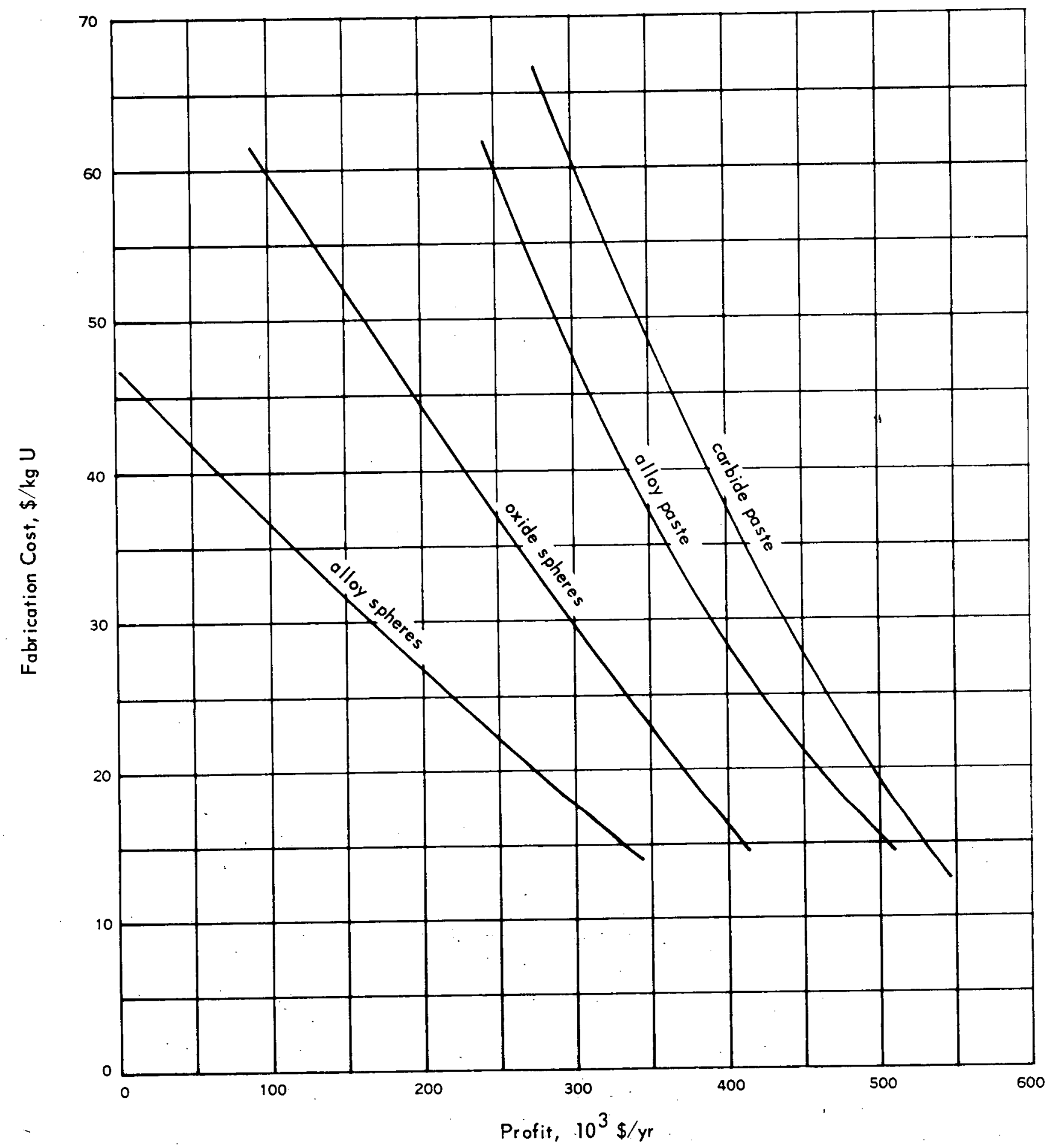

FIG. 5 PROFITS FOR MOBILE BLANKETS 
to about 0.1 mill per kwhr electric of core power. With about 0.3 mill per kwhr electric of core power as the maximum total profit obtainable from a mobile system, the profit differential between paste and cladsphere systems becomes significant and justifies the selection of a paste blanket for a reactor system covered by the aforementioned ground rules. This statement assumes that there are no gross differences between the systems, other than economics, that would be vital in a choice between the two.

In order to determine whether there is some simple method to increase the profits of a mobile blanket, two brief studies were made. In one, a paste blanket was divided into zones $10 \mathrm{~cm}$ thick, with the paste in a given zone completely isolated from the paste in the other zones. It was found that there is no significant economic advantage to this type of mobile blanket. This is in direct contrast to the fixed blanket. There, the blanket pins in the outer regions which have lower heat-generation rates can be fabricated at a comparatively lower cost. No such economic advantage can be obtained with the paste blanket since the paste is the same in physical form throughout the blanket.

The second study was an investigation into the potential of enriched blanket material. This effort was prompted by the observation that the buildup of plutonium changes the reaction rates in the direction that enhances the profit. For a simple case for study, the enrichment was fixed at $10 \%$ plutonium concentration so that the plutonium would build up at the same rate that it is burned out, keeping the net plutonium concentration constant throughout the blanket lifetime. An analysis of this situation showed that the plutonium inventory charges on the relatively high concentration of plutonium in such a blanket would cause the profits achievable with such a blanket to be several hundred thousand dollars per year less than those achievable from a similar blanket that was started with depleted uranium.

Thus, neither of the simple ideas which were tried produced a substantial increase in profits. 
COMPARISON OF MOBILE BLANKETS WITH

FIXED BLANKETS

The analyses of fixed blankets in Reference 1 show that a blanket of $\mathrm{UO}_{2}$ pins is far more profitable than a blanket of uraniumalloy pins. This is mainly due to spectrum effects and burnup limitations on the alloy. The profit achievable with a well-designed and properly operated fixed oxide-pin blanket is about $\$ 337,500$ per year assuming a nominal economic climate. In order to evaluate the mobile blanket economics properly and make a just comparison, it is necessary to review some of the assumptions used in the economic analysis. First, it was assumed that the capital charges associated with the blanket would be considered to be independent of the type of blanket and would be assessed against the core. This same assumption was made with respect to operating and maintenance costs to simplify economic analysis of the blanket. Thus, it was not necessary to evaluate the cost increase of the fuelhandling mechanism, the reactor, the primary coolant systems, and many other items, due to the mere existence of the blanket. This certainly is justifiable for all fixed-blanket systems. The most significant differences could be in the additional capital charges necessary for slight increases in such things as the diameter of the reactor vessel and arms of the fuel-handling mechanism if a thicker blanket were being considered. It is estimated that these differences will be small relative to the over-all costs of the items. It is, therefore, reasonable to neglect these differences when comparing fixed blankets.

The profits for the mobile blankets are shown in Figure 5. These results should be compared with the profits of the best fixed oxide-pin blanket, i.e., $\$ 337,500 / y r$. Thus, from Figure 5 it is clear that in order to match fixed oxide pins, it is necessary to fabricate alloy spheres for about $\$ 15 / \mathrm{kg} U$ and oxide spheres for about $\$ 25 / \mathrm{kg}$ U. By the same standard it is necessary to fabricate alloy paste for $\$ 40 / \mathrm{kg} U$ and carbide paste for $\$ 52 / \mathrm{kg} U$. A comparison of the break-even costs with the estimated fabrication costs shows that, for the clad-sphere.concepts, the break-even cost is lower than the estimated fabrication costs and, for the paste concepts, the break-even cost is much higher than the estimated fabrication cost. Thus, it would be difficult to make a cladsphere blanket that would be economically competitive to a fixed oxidepin blanket. But it would be easy to do so with a paste blanket -- even if fabrication costs of such a blanket were 20 to $50 \%$ higher than the highest estimation.

The mobile systems that have been considered in this study have a common economic factor that has been neglected thus far. Both the 
paste system and the clad-sphere system require a circulation system to move the fuel continuously around a closed circuit in order to achieve the inherent advantages of mobile systems. The cost of this circulation system must be charged against the blanket, regardless of the type of core which is considered.

Since this study was confined to only the basic design and economic factors, the design of a circulating system was not undertaken. Concepts which might be feasible were outlined, however, but no firm cost estimate for a circulation system can be made at this time. If the capital cost for a circulation system would be one million dollars, the annual fixed charge associated with this item would be $\$ 130,000$ per year. Consequently, the profits given above would have to be reduced and the comparison with the fixed blanket adjusted accordingly.

From the results given above, it is clear that, in an economic sense, the paste blanket is the better of the two mobile blankets studied if there are no factors other than economics to influence a choice. And, it is appreciably superior, economically, to the fixed blanket. In addition, there may be situations where a mobile blanket may be preferable to a fixed blanket for mechanical reasons. Typical of these would be a reactor with a mobile core or a core of unusual geometry, such as a cone or a sphere. In such situations it would be possible to use a good mobile blanket that has attractive economics.

The indicated economic superiority of the paste blanket justifies further development of this concept. Investigation in further detail, with proof-of-principle and in-pile studies, would permit the design of a more refined paste blanket than was attempted in this initial study.

Although all of these conclusions were drawn from a specific situation and are known to be applicable only to the situation studied, they should be generally true for a wide range of fast reactor designs. The absolute values may change somewhat; however, the general comparisons between ceramic and alloy, between spheres and paste, and between mobile and fixed blankets should still be valid. 


\section{REFERENCES}

(1) APDA -156, Design and Economic Evaluation of Fixed Blankets For Fast Reactors, August 30, 1963

(2) APDA-146, Conceptual Design of a 300-Mwe Paste-Fueled Fast Breeder Power Reactor, October, 1961

(3) BNL -5830, Settled Bed Fuel Reactors, November, 1961

(4) BNL-713 (T-250), The Settled Bed Fast Reactor Status Report, January 20, 1962

(5) Foust, A. S., et al, Principles of Unit Operations, John Wiley \& Sons, Inc., New York (1960)

(6) CF-60-6-122, Review of Information on U-Mo Alloys and U-Mo-UO 2 Dispersion Fuels, June 30, 1960

(7) Gibson, J. O., and Weidman, R., Chemical Synthesis Via the High Intensity Arc Process, Chemical Engineering Process: 59, 9 (1963)

(8) BMI-APDA -642, Engineering and Nuclear Design Phases of a Paste Fuel Irradiation Experiment, June 4, 1958

(9) Wahll, M. J., et al, Spheroidization of Ir regularly Shaped Metal Powders, Powder Metallurgy: 8, 48 (1961)

(10) HW-51770, Fabrication of $\mathrm{UO}_{2}$ Fuel Element Shapes by Hydrostatic Pressing, August 1, 1957

(11) Hasnain, S. A., and Okrent, D., On the Design and Management of Fast Reactor Blankets, Nuclear Science and Engineering: 9, $314-322(1961)$ 


\section{APPENDIX I - THE CHOICE OF A CERAMIC MATERIAL AS A PASTE DISPERSANT}

In the paste blanket it is necessary to achieve operation with a design which meets the demands of fabrication and rheology. These basic considerations lead to the requirement that the diameter and pitch of the coolant tubes have dimensions on the order of several tenths of an inch, with the pitch-to-diameter ratio sufficiently large (about 1.3) to achieve a high paste-volume fraction. The ligament size, or spacing between the coolant tubes, is determined by the consideration that the sodium carrier fluid in the paste must not be allowed to boil. This sets the maximum paste temperature. Since the paste temperature at the surface of the coolant tube is fixed primarily by the coolant temperatures, which are fixed in this study, the ligament size, then, is determined primarily by the thermal conductivity of the paste.

Very little work has been done on the thermal conductivity of paste or similar materials, especially where the differences between the conductivities of the carrier and the dispersant are very large. This is true of $\mathrm{UO}_{2}$ paste; by use of various correlations, its conductivy has been estimated at between 7 and $14 \mathrm{BTU} / \mathrm{hr}-\mathrm{ft}-\mathrm{F}$. Due to this uncertainty, tube and ligament sizes could be in error by $30 \%$. Moreover, alternate blanket designs based on $\mathrm{UO}_{2}$ paste would be difficult to fabricate because of smaller tube diameters and closer spacing, and they might not meet the rheology standards with the particle size ( 200 microns) being considered in this study.

When the conductivity difference between the components is small, any one of several correlations can be used to estimate the conductivity of the paste, since all of the standard correlations agree quite well. UC paste is one of those materials. The conductivity of UC paste can be estimated quite closely at about $20 \mathrm{BTU} / \mathrm{hr}-\mathrm{ft}-\mathrm{F}$. Consequently, on the basis of available information, a UC paste blanket can be designed with a high degree of confidence. In addition, the UC paste blankets described in this report meet the standards of feasibility of fabrication and adequate rheological conditions.

One conclusion, then, is that, although a $\mathrm{UO}_{2}$ paste blanket might be feasible, a UC paste blanket certainly would have a simpler and cheaper radiator structure. Since there is no compelling reason to consider a $\mathrm{UO}_{2}$ paste blanket further, a UC paste blanket was selected as the ceramic paste blanket that should be studied.

A product of this analysis was that, since little is known about the thermal conductivity of paste, an experimental program of dynamic 
measurement to acquire these data should be initiated to permit confident design work in the future phases of this project.

The considerations that led to the choice of UC paste over $\mathrm{UO}_{2}$ paste would not be applicable to pins or spheres. The high-temperature performance of UC was not a factor in the paste analysis, since the boiling point of the sodium carrier in the paste is an overriding consideration. However, in pins and spheres, the advantages of high conductivity in UC are overridden by the relatively low temperatures which must be maintained in order to keep the material stable. Thus, pin and sphere diameters would be about the same in both $\mathrm{UO}_{2}$ and $\mathrm{UC}$ systems; for this reason, no appreciable savings in fabrication cost or appreciable increase in fuel volume fraction could be realized in choosing UC over $\mathrm{UO}_{2}$ for those geometries. In order to base the study on present-day technology as much as possible, it is, therefore, justifiable to choose $\mathrm{UO}_{2}$ over $\mathrm{UC}$ for a ceramic material for pins and spheres, but to consider UC as the ceramic material to be used in a paste system. 


\section{APPENDIX II - ASSUMED FABRICATION PROCESSES \\ FOR PASTE AND SETTLED BED \\ BLANKET MATERIALS}

Spherical UC Powder

1. Starting materials are $\mathrm{UO}_{2}$ and high purity carbon (as graphite). These are blended together $\left(11 \% \mathrm{C}, 89 \% \mathrm{UO}_{2}\right)$ and made into homogeneous consumable electrodes. Cost of making electrodes is estimated at about $\$ 0.23 / 1 b$.

2. The consumable electrode is used as the anode in the plasma-torch apparatus, where a high-intensity arc (4000-5000 K) melts the tip of the electrode, causing the $\mathrm{UO}_{2}$ and $\mathrm{C}$ to react and form $\mathrm{UC}$. As the molten UC forms, droplets are blown off and are condensed by an inert gas stream.

3. UC particles are near theoretical density and are spherical in shape. Particle size is a function of surface tension forces and characteristics of the plasma stream. Sizes may range from 44 to $2000 \mu ; 1 / 4$-inch spheres are ideal from a plasma standpoint.

4. Losses are essentially limited to gaseous reactants. About $83 \%$ of the initial charge is converted to $\mathrm{UC}$, the remainder being carbon monoxide. Off-size UC particles can probably be recycled by melting and casting into consumable electrodes.

\section{Spherical U -3 w/o Mo alloy Powder}

1. Starting materials are uranium metal and high-purity molybdenum. These are alloyed in an induction-heated vacuum furnace.

2. In the spinning-disk method, the $\mathrm{U}-3 \mathrm{w} / \mathrm{o}$ Mo is made into powder, directly after alloying, within a suitably constructed vacuum-tight chamber integral with the melting furnace. The molten alloy is poured onto a contoured ceramic disk that is rotating rapidly; the stream, upon contact with the spinning disk, is broken up and thrown into droplets which solidify as spherical particles.

3. Particle size is principally affected by the pouring temperature of the alloy. Only about $66 \%$ of the alloy charge is converted to powder; of this, about $47 \%$ of the particles are in the 150-410 $\mu$ size range, about $44 \%$ are greater than $410 \mu$, and the remainder are less than $150 \mu$. 
4. The approximate $40 \%$ loss consists of splash and disk skulls that can be recycled to some extent as alloy melt stock.

5. Off-size powder can be salvaged and recycled as alloy melt stock.

6. It may also be possible to produce spherical U-3 Mo alloy powder by the drop-shot method using, as starting material, irregularly shaped powder made by mechanical attrition (e.g., ball milling or crushing) or by hydriding of alloy stock previously prepared in a form suitable for either method.

7. The irregularly shaped powder is made spherical in the following manner. Within the controlled atmosphere of a protective chamber, the individual particles are melted as they free-fall past an induction coil, 'and are solidified into a spherical shape as they fall farther into a cooler part of the chamber.

8. The size of the final particle is obviously limited by the particle size of the starting material. Should the range of acceptable final sizes be narrow, the effect on cost can be appreciable; costs incurred with particles ranging from 150 to $180 \mu$ would perhaps be twice those incurred with particles ranging from 44 to $180 \mu$.

9. Spherical powder might be produced by atomization in a manner analogous to the plasma-torch method. Here, two electrodes of U-3 w/o Mo alloy are used to create an arc, causing localized melting of the alloy at the electrode tips. A high-velocity stream of inert gas is directed into the center of the arc; droplets of alloy are blown off and are condensed into spherical particles.

10. Although this technique (item No. 9) has yet to be reasonably demon strated, it is potentially cheaper than the spinning disk method; a larger yield of desirable (larger) particle sizes would be produced with essentially all losses in the form of off-size particles that can be recycled by remelting and casting into electrodes.

\section{U-3 w/o Mo Spheres (approximately $1 / 2$-inch diameter)}

1. Starting materials are uranium metal and high-purity molybdenum. These are alloyed in an induction-heated vacuum furnace and the alloy is cast into ingot form for subsequent extrusion.

2. Rod stock for forging is formed from the ingots by hot extrusion (at about $1600 \mathrm{~F}$ ). Croppings at both ends of the rod stock can be recycled as ingot melt stock. 
3. Automatic forging presses are employed which pre-heat the rod stock, shear the heated rod into small slugs as it is fe'd into the press, then feed and orient the slugs into the die cavity, where they are forged into spheres. Vendor preference and equipment limitations will determine the type of cooling employed subsequent to forging; but in any event, the U-3 w/o Mo spheres must have a heattreated structure in their final form, and not a quenched structure.

4. Flashing (circumferential irregularity) resulting from forging can be removed from the spheres by grinding or by tumbling.

5. Coating of the U-3 w/o Mo spheres with either $\mathrm{Nb}, \mathrm{W}$, or $\mathrm{Zr}$ may be posible by chemical-vapor deposition using the metalhalide, fluidized-bed process. The size and weight of individual $\mathrm{U}-3 \mathrm{w} / \mathrm{o}$ Mo spheres are appreciably greater than other nuclear materials, specifically $\mathrm{UO}_{2}, \mathrm{UC}$ and $\mathrm{UC}_{2}$, which have received considerable attention as coated particles produced by the fluidized bed process. It is assumed that the basic principle of chemicalvapor deposition is applicable, and that modifications to existing techniques are possible in order to accommodate the relatively large U $-3 \mathrm{w} / \mathrm{o}$ Mo spheres.

6. Losses would seem to be low, and largely confined to the rodextrusion and sphere-grinding operations.

$\mathrm{UO}_{2}$ Spheres (approximately $1 / 2$-inch diameter)

1. Starting material is fused $\mathrm{UO}_{2}$ prepared by the ammonium diurinate process, assuming initial material is depleted $\mathrm{UF}_{6}$. The $\mathrm{UO}_{2}$ powder is prepared for cold pressing by wet and/ or dry ball-milling and screening to remove over-size particles (which can be recycled).

2. A binder, such as polyethylene glycol, is added to the $\mathrm{UO}_{2}$ which; after blending, produces a free-flowing granular powder which breaks up readily when cold pressed. The binder also lends strength to the unsintered compact and provides internal lubrication during pressing.

3. Spheres are formed by cold pressing and are sintered in hydrogen to obtain maximum density. The sintering operation incorporates a pre-firing cycle to volatilize and remove the binder.

4. The as-sintered spheres may be metal-coated and not require any grinding to improve spheroidicity. Coatings of $\mathrm{Nb}, \mathrm{W}$ or $\mathrm{Zr}$ may. be applied by chemical-vapor deposition as for the U-3 Mo spheres. 
5. Losses, as such, would largely be confined to recoverable scrap resulting from "breakage" during pressing or sintering of the $\mathrm{UO}_{2}$ spheres. Because of their shape, handling losses of the spheres would seem to be less than for cylindrical pellets. Fabrication yield is assumed to be high for the cold pressing and sintering operations and also for the metal-coating operation. Just what the latter would be is presently a matter of speculation. 


\section{APPENDIX III - PHYSICS ANALYSIS OF MOBILE SYSTEMS}

From the results of the economic analysis, the relative importance of various economic items can be determined. For the economic conditions considered, the production and sale of plutonium produces more income than does the production and sale of heat. This is due primarily to the spectrum that existed in the blankets studied. The fast spectrum is efficient in the production of plutonium, relative to the production of heat by fission. In addition, the spectrum is such that during the time that a given mass of blanket material is in the blanket, there is always a net increase in plutonium concentration. Therefore, it is never possible to burn in situ all of the plutonium produced in the blankets that were studied.

Burning in situ might be accomplished by using a multi-region blanket and movable fuel. Certain regions of this blanket could be de signed to have a fast spectrum and other regions could have a thermal spectrum. 'With this design, it might be possible to produce plutonium in the regions with a fast spectrum and burn it in the regions with a thermal spectrum. Such a system merits investigation in some future blanket study.

A generalization can be drawn from the statements made in the first paragraph of this appendix. That is, for the fast-spectrum blankets considered in this study, it is more important for a U -238 atom to be involved in a capture reaction than in a fission reaction. Consequently, the capture rate for $\mathrm{U}-238$ is the most important reaction rate to consider when making a qualitative judgement of the economics of a given system from the results of a physics analysis. Although specific profit, expressed in units of $\$ / \mathrm{kg} \mathrm{U}$, is a function of the reaction rates, the total profit is the product of the specific profit and the mass of uranium in the blanket. Consequently, in order to determine the relative economic rankings of similar blankets, the uranium masses must be compared, as well as the U -238 capture rates. Thus, in comparing two systems with comparable lifetimes, the one with the greater uranium mass and U-238 capture rates will be the most profitable. However, if one of these quantities is larger and the other is smaller, no generalization can be drawn. Such a situation would require a full economic analysis.

A list of data for typical mobile blanket systems is given in Table VIII. Note that using the above criterion, the ceramic paste can be predicted to be more profitable than the alloy paste. However, the above criterion does not permit any judgement to be made about the sphere systems since the reaction rates and the $U-238$ masses move inversely. 
It is difficult to compare two systems using the results of a physics analysis if there is a large difference in their lifetimes. As it has been shown in Reference 1 , fabrication cost is a major component of the total cost, and systems with the same fabrication cost but different lifetimes would have different proration rates for this cost. Such information is not obtainable from a physics analysis. Thus, although the ceramic-sphere and paste systems have comparable U -238 capture rates, the lifetime of the former is effectively limited by the engineering limitation on heat-generation rate. No such limitation exists for the paste concepts.

The effect of lifetime can be seen in Table VIII. The longer life time associated with paste blankets makes them economically more attractive than sphere blankets, even though for certain designs they might be very similar from the standpoints of reaction rate and $U-238$ mass.

Consequently, it can be generalized from the foregoing that only certain limited economic conclusions can be made, especially when comparing systems that have large differences in blanket lifetime. 
TABLE VIII - REPRESENTATIVE DATA FOR ECONOMIC COMPARISONS

\begin{tabular}{cccc}
$\begin{array}{c}\text { Average } \\
\text { U-238 }\end{array}$ & U-238 & & \\
Capture Rate & Mass & Profit & Lifetime \\
(capture/atom-yr) & $\underline{(\mathrm{kg})}$ & $\underline{(\mathrm{yr})}$ & $\underline{(\mathrm{yr})}$ \\
\hline
\end{tabular}

$\begin{array}{lcccc}\text { Alloy spheres } & 0.0039 & 26,100 & 170,000 & 2.9 \\ \text { Ceramic spheres } & 0.0051 & 20,500 & 300,000 & 3.4 \\ \text { Alloy paste } & 0.0053 & 19,080 & 391,000 & 4.8 \\ \text { Ceramic paste } & 0.0055 & 21,720 & 438,000 & 4.6\end{array}$

